\title{
Medical Image of the Month: Pectus Excavatum
}

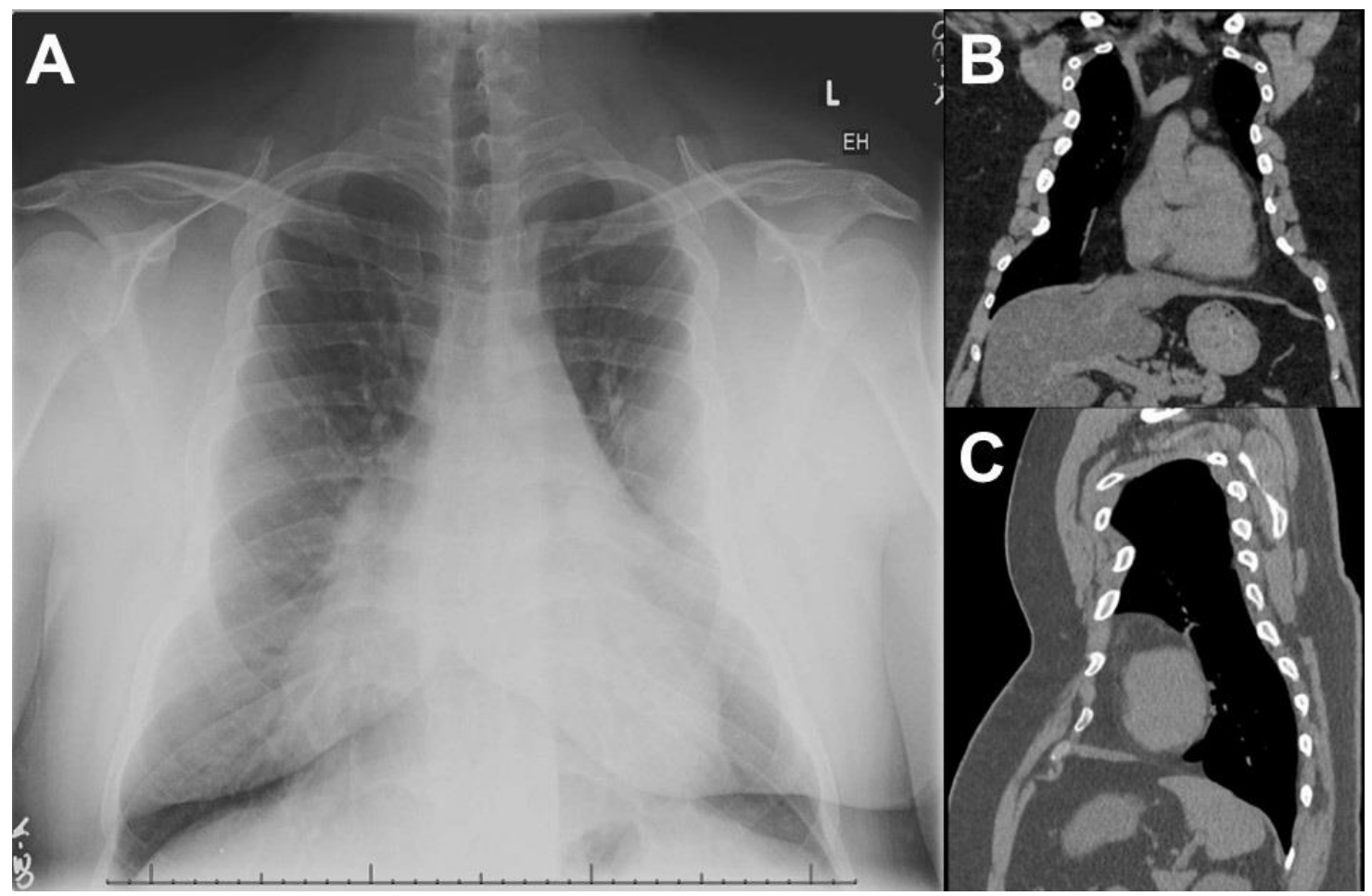

Figure 1. A) PA chest radiograph at 38 years old demonstrates rib cage growth arrest at the time of pectus repair. B) and C) demonstrate the coronal and sagittal CT chest views.

\begin{tabular}{|c|c|c|c|c|c|c|c|c|c|c|}
\hline \multirow{2}{*}{\multicolumn{2}{|c|}{ Spirometry }} & \multicolumn{6}{|c|}{ Pre-Bronchodilator } & \multicolumn{3}{|c|}{ Post-Bronchodilator } \\
\hline & & (BTPS) & \multirow{2}{*}{$\begin{array}{l}\text { BEST } \\
2.04\end{array}$} & \multirow{2}{*}{$\begin{array}{l}\text { PRED } \\
4.89\end{array}$} & \multirow{2}{*}{$\begin{array}{l}\text { \%PRED } \\
42\end{array}$} & \multirow{2}{*}{$\begin{array}{l}\text { LLN } \\
4.03\end{array}$} & \multirow{2}{*}{$\begin{array}{l}\text { ULN } \\
5.75\end{array}$} & \multirow{2}{*}{$\begin{array}{l}\text { BEST } \\
2.16\end{array}$} & \multirow{2}{*}{$\begin{array}{c}\text { \%PRED } \\
44\end{array}$} & \multirow{2}{*}{$\begin{array}{c}\% \text { Chg } \\
6\end{array}$} \\
\hline FVC & Liters & & & & & & & & & \\
\hline FEV1 & Liters & & 1.65 & 3.93 & 42 & 3.20 & 4.66 & 1.76 & 45 & 7 \\
\hline FEV1/FVC & & & 81 & 80 & & 71 & 90 & 82 & & \\
\hline FEV $1 / N C$ & $\%$ & & 79 & & & & & 82 & & \\
\hline FEV1/FEV6 & $\%$ & & 81 & 82 & & 73 & 91 & 82 & & \\
\hline FEF $25-75 \%$ & $\mathrm{~L} / \mathrm{sec}$ & & 1.64 & 3.82 & 43 & & & 1.92 & 50 & 17 \\
\hline PEF & $\mathrm{L} / \mathrm{sec}$ & & 4.31 & 9.62 & 45 & 7.47 & 11.76 & 4.42 & 46 & 2 \\
\hline PIF & $\mathrm{U} / \mathrm{sec}$ & & 2.05 & & & & & 2.44 & & 19 \\
\hline FIF $50 \%$ & U/sec & & 1.88 & & & & & 1.83 & & -3 \\
\hline FEF $50 \%$ & $\mathrm{~L} / \mathrm{sec}$ & & 2.38 & & & & & 3.02 & & 27 \\
\hline
\end{tabular}

\begin{tabular}{|c|c|c|c|c|c|c|c|c|}
\hline \multicolumn{9}{|c|}{ Lung Volumes } \\
\hline TLC & Liters & 3.48 & 6.58 & 53 & 5.43 & 7.73 & & \\
\hline VC & Liters & 2.09 & 4.89 & 43 & 4.03 & 5.75 & 2.16 & 44 \\
\hline RV & Liters & 1.39 & 1.85 & 75 & 1.17 & 2.52 & & \\
\hline FRC PL & Liters & 1.73 & 3.25 & 53 & 2.27 & 4.24 & & \\
\hline ERV & Liters & 0.32 & 1.58 & 20 & 1.21 & 1.95 & 0.30 & 19 \\
\hline IC & Liters & 1.75 & 3.16 & 55 & 2.43 & 3.90 & 1.79 & 57 \\
\hline RVITLC & $\%$ & 40 & 29 & & & & & \\
\hline Vtg & Liters & 1.73 & & & & & & \\
\hline
\end{tabular}

$\begin{array}{llrrrrr}\text { Diffusion Capacity (DLCO) } & & & & & \\ \text { DLCO } & \mathrm{mL} / \mathrm{mmH} / \mathrm{min} & 23.6 & 38.9 & 61 & 31.41 & 46.46 \\ \text { KCO (DL/NA) } & \mathrm{mL} / \mathrm{mHg} / \mathrm{min} / \mathrm{L} & 8.40 & 6.00 & 140 & 4.69 & 7.32 \\ \text { VA } & \text { Liters } & 2.81 & 6.55 & 43 & & \\ \text { VI } & \text { Liters } & 2.06 & & & & \end{array}$

Figure 2: Pulmonary function tests demonstrate severe restrictive ventilatory defect. 


\section{Clinical History}

A 38-year-old man with obesity and history of pectus excavatum post-operative surgical repair at age 4 presented to the general pulmonary clinic with symptoms of severe dyspnea on exertion after walking one block. Chest x-ray and thoracic CT scan demonstrate anterior chest wall depression. (Figure 1). Pulmonary function testing demonstrated a severe restrictive lung disease (Figure 2). High resolution CT demonstrated anterior chest wall depression. The Haller index was 2.5-mild excavatum - with associated scarring in the anterior right lung. Expiratory air-trapping was seen consistent with small airways disease.

\section{Haller Index}

The Haller index is calculated by dividing the transverse diameter of the chest by the anterior-posterior distance on the CT of the chest on the axial slice that demonstrates the smallest distance between the anterior surface of the vertebral body and the posterior surface of the sternum (1). Normal chest <2.0; mild excavatum $2.0-3.2$; moderate excavatum $3.2-3.5$; severe excavatum $>3.5$. Corrective surgery is considered for a Haller index of greater than or equal to 3.25. Secondary thoracic dystrophy is a known consequence of too early repair of pectus excavatum (1). Cases like our patient have changed when surgical repair is attempted until after puberty.

Michael Insel, MD and Janet Campion, MD

Division of Pulmonary, Allergy, Critical Care and Sleep Medicine

Banner University Medical Center-Tucson

Tucson, AZ USA

\section{Reference}

1. Haller JA Jr, Colombani PM, Humphries CT, Azizkhan RG, Loughlin GM. Chest wall constriction after too extensive and too early operations for pectus excavatum. Ann Thorac Surg. 1996 Jun;61(6):1618-24. [CrossRef] [PubMed] 